\title{
Imiquimod does not elicit inflammatory responses in the skin of the naked mole rat (Heterocephalus glaber)
}

\author{
Mosiany Letura Kisipan ${ }^{1,4^{*}} \mathbb{0}$, Rodi Omondi Ojoo ${ }^{2}$, Titus I. Kanui ${ }^{3}$ and Klas S. P. Abelson ${ }^{4}$
}

\begin{abstract}
Objective: Naked mole rat (Heterocephalus glaber) has recently attracted interest in biomedical research due to its exceptional longevity, cancer resistance and tolerance to potentially harmful conditions or stimuli. Given its unique attributes, this study was designed to characterize inflammatory skin reactions of this animal to topical application of imiquimod, a toll-like receptor 7 and 8 agonist that triggers psoriasis-like skin reaction.

Results: Imiquimod did not cause the expected psoriasis-like skin changes. There was no epidermal thickening and a straight epidermo-dermal boundary was maintained. There was no parakeratosis and the granular layer of epidermis was well formed. In the dermis, there was no leukocyte infiltration. This points to an exceptional nature of inflammatory/immune responses of this animal, but the mechanism could not be explained by our results. Naked mole rat could be a valuable negative model for studying psoriasis and other inflammatory skin conditions but as a prerequisite, there is need for further investigations to establish the mechanisms behind its lack of response to imiquimod.
\end{abstract}

Keywords: Naked mole rat, Imiquimod, Skin, Inflammation, Psoriasis, Negative model

\section{Introduction}

The naked mole rat, NMR (Heterocephalus glaber), is a Bathyergid rodent distributed in the hot and dry regions of the horn of eastern Africa [1,2]. NMRs are unique in in that they are eusocial, poikilothermic, and exhibit extreme longevity with minimal signs of aging $[1,3-6]$. The skin of this animal is loosely folded over the body and lacks pelagic hairs, hair follicles, sweat and sebaceous glands [7]. The junction between epidermis and dermis is regular with no epidermal ridges nor dermal papillae and the melanocytes are found within the dermis.

Psoriasis is a chronic immune-mediated inflammatory skin disease with strong genetic predisposition and a high prevalence in adults than in children [8-12]. It is characterized by well demarcated erythematous, indurated and

\footnotetext{
*Correspondence: kisipanm@gmail.com; mosiany.kisipan@egerton.ac.ke ${ }^{1}$ Department of Veterinary Anatomy \& Physiology, Egerton University, Egerton, P.O. Box 536, Nakuru 20115, Kenya

Full list of author information is available at the end of the article
}

pruritic skin plaques covered by silvery scales $[9,12-14]$. Though predominantly a skin disease, psoriasis is associated with arthritis, cardiovascular diseases and other comorbidities [9, 14, 15]. Histopathological features of psoriasis include a thickened epidermis (acanthosis) due to increased keratinocyte proliferation with loss of granular layer, thickened stratum corneum (hyperkeratosis) and retention of nuclei in outer layers of epidermis and stratum corneum (parakeratosis). There are also collections of neutrophils in epidermis including stratum corneum referred to as Munro's microabscesses. In the dermis, there is dilation and increase in blood vessels and infiltration of inflammatory cells $[9,16,17]$.

Imiquimod (IMQ) is a toll-like receptor (TLR) 7 and 8 agonist used topically to treat external genital and perianal warts caused by human papilloma virus, actinic keratosis and superficial basal cell carcinomas and potential to treat many other skin disorders [18-26]. Through activation of its receptors, IMQ application, even on a

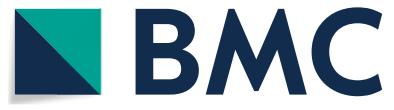

(c) The Author(s) 2020. This article is licensed under a Creative Commons Attribution 4.0 International License, which permits use, sharing, adaptation, distribution and reproduction in any medium or format, as long as you give appropriate credit to the original author(s) and the source, provide a link to the Creative Commons licence, and indicate if changes were made. The images or other third party material in this article are included in the article's Creative Commons licence, unless indicated otherwise in a credit line to the material. If material is not included in the article's Creative Commons licence and your intended use is not permitted by statutory regulation or exceeds the permitted use, you will need to obtain permission directly from the copyright holder. To view a copy of this licence, visit http://creativeco mmons.org/licenses/by/4.0/. The Creative Commons Public Domain Dedication waiver (http://creativecommons.org/publicdomain/ zero/1.0/) applies to the data made available in this article, unless otherwise stated in a credit line to the data. 
short-term basis, triggers inflammatory skin reactions that closely resemble those seen in psoriasis [27-30]. The use of this regimen in mice has since been preferred as a model for studying the condition [30-34].

NMRs resist or tolerate various potentially harmful conditions or stimuli including hypoxia [35], inflammatory pain [36], histamine-induced itch [37] and cancer [38-40]. Due to these traits and its extreme longevity, the animal has attracted a lot of interest in biomedical research [41]. Given its resistance and unique skin structure, the animal could be a good model to study psoriasis and other skin disorders.

This study was designed to characterize the responses of the skin of NMR to topical application of IMQ by describing both the macroscopic and histological changes as a step in exploring whether the animal could be a model for studying psoriasis and other skin conditions.

\section{Main text}

\section{Materials and methods}

Animals, husbandry, and study design

A total of 22 NMRs from a colony captured from Kibwezi in Makueni County, Kenya, were kept in a dark temperature-controlled room at the main campus of the South Eastern Kenya University (SEKU). The animals were housed in Perspex cages with interconnected compartments and wood shavings as bedding material. After three weeks of acclimatization, the animals were randomly re-distributed to four groups of 5-6 animals housed in separate cages and then randomly assigned to different treatments as shown in Table 1. No power analysis was made for group size determination. Given the nature of the study, a group size of 5-6 animals was considered sufficient and supported by the Resource Equation Method [42]. A further three weeks acclimatization period was allowed before the start of the treatments. In brief, two groups, which served as controls, received topical Vaseline over the shoulder region (Group I) or over the rump (Group II). The other animals

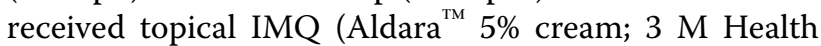

Care Limited, United Kingdom), which was also applied over the shoulder region (Group III) and over the rump (Group IV). Vaseline was applied once daily at 09:00 $\mathrm{h}$ for eight consecutive days while imiquimod was applied twice daily at 09:00 $\mathrm{h}$ and 16:00 $\mathrm{h}$ for eight consecutive days as summarized in Table 1. The duration of testing was based on previous studies in mice [32,33]. All test agents were applied on the skin on an area approximately 1 and $2 \mathrm{~cm}^{2}$ respectively over the shoulder and rump. In all animals, the area of application was examined daily for any changes. At the end of the treatments, the animals were anesthetized using isoflurane immediately followed by euthanasia by decapitation.

\section{Samples collection, processing, and examination}

Full thickness skin from sites where topical test agent was applied was dissected out, fixed with $10 \%$ buffered formalin, processed for wax embedding then sectioned, mounted on glass slides and stained with hematoxylin and eosin. Coverslips were applied using DPX mountant. The mounted sections were examined by two blinded examiners using a Leica DM 500 light microscope connected with a Leica ICC 50 digital camera (Leica Microsystems, Wetzler, Germany).

\section{Results}

\section{i) Macroscopic IMQ response}

No signs of erythema, scaling or any other skin changes were observed on the area of the skin where Vaseline or IMQ was applied (Fig. 1 and Additional file 1: Figure S1).

ii) Histopathological findings

The epidermis did not show any thickening in all the groups, and a straight boundary between the epidermis and dermis was maintained with no rete ridges (Fig. 2 and Additional file 2: Figure S2). No parakeratosis or Munro's micro-abscesses were present, and the granular layer was well formed. In the dermis,

Table 1 Summary of the study design

\begin{tabular}{|c|c|c|c|c|c|c|c|c|c|c|c|c|c|c|c|c|c|c|c|}
\hline \multirow[t]{3}{*}{ Groups } & \multirow[t]{3}{*}{$\mathrm{n}$} & \multicolumn{18}{|c|}{ Time of application } \\
\hline & & \multicolumn{2}{|c|}{ Day 1} & \multicolumn{2}{|c|}{ Day 2} & \multicolumn{2}{|c|}{ Day 3} & \multicolumn{2}{|c|}{ Day 4} & \multicolumn{2}{|c|}{ Day 5} & \multicolumn{2}{|c|}{ Day 6} & \multicolumn{2}{|c|}{ Day 6} & \multicolumn{2}{|c|}{ Day 7} & \multicolumn{2}{|c|}{ Day 8} \\
\hline & & 9:00 & $16: 00$ & $9: 00$ & $16: 00$ & 9:00 & $16: 00$ & 9:00 & $16: 00$ & 9:00 & $16: 00$ & $9: 00$ & $16: 00$ & 9:00 & $16: 00$ & $9: 00$ & $16: 00$ & $9: 00$ & $16: 00$ \\
\hline 1 & 6 & VAS & - & VAS & - & VAS & - & VAS & - & VAS & - & VAS & - & VAS & - & VAS & - & VAS & - \\
\hline$\|$ & 6 & VAS & - & VAS & - & VAS & - & VAS & - & VAS & - & VAS & - & VAS & - & VAS & - & VAS & - \\
\hline III & 5 & $\mathrm{IMQ}$ & IMQ & IMQ & IMQ & $\mathrm{IMQ}$ & IMQ & IMQ & IMQ & IMQ & IMQ & IMQ & $\mathrm{IMQ}$ & IMQ & IMQ & IMQ & IMQ & $\mathrm{IMQ}$ & IMQ \\
\hline IV & 5 & IMQ & - & $\mathrm{IMQ}$ & - & $\mathrm{IMQ}$ & - & IMQ & - & $\mathrm{IMQ}$ & - & $\mathrm{IMQ}$ & - & $\mathrm{IMQ}$ & - & $\mathrm{IMQ}$ & - & IMQ & - \\
\hline
\end{tabular}

VAS Vaseline, IMQ imiquimod 

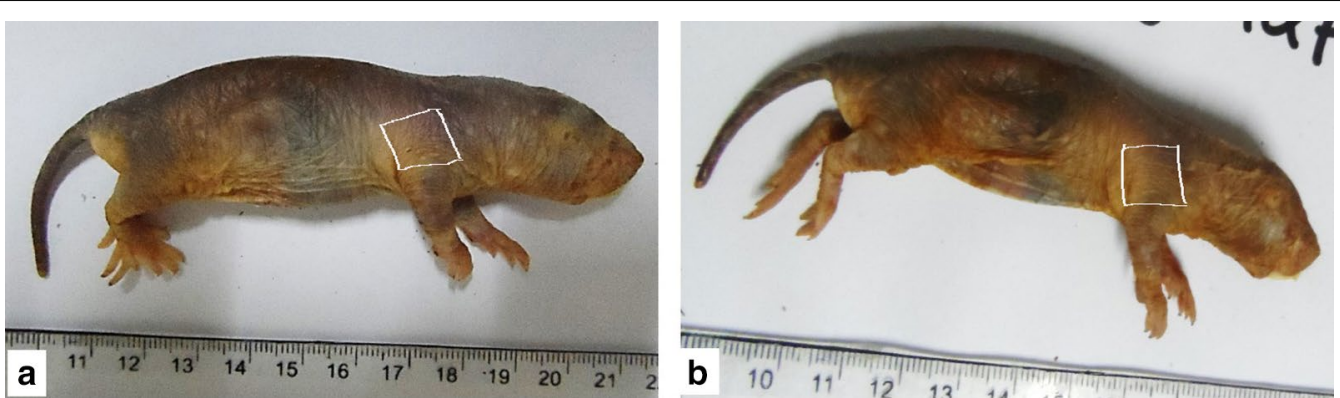

Fig. 1 NMR that received topical Vaseline (a) and IMQ (b) over the shoulder region (under the area marked with the white line). IMQ did not induce any changes in the skin. Calibrations are in centimeters
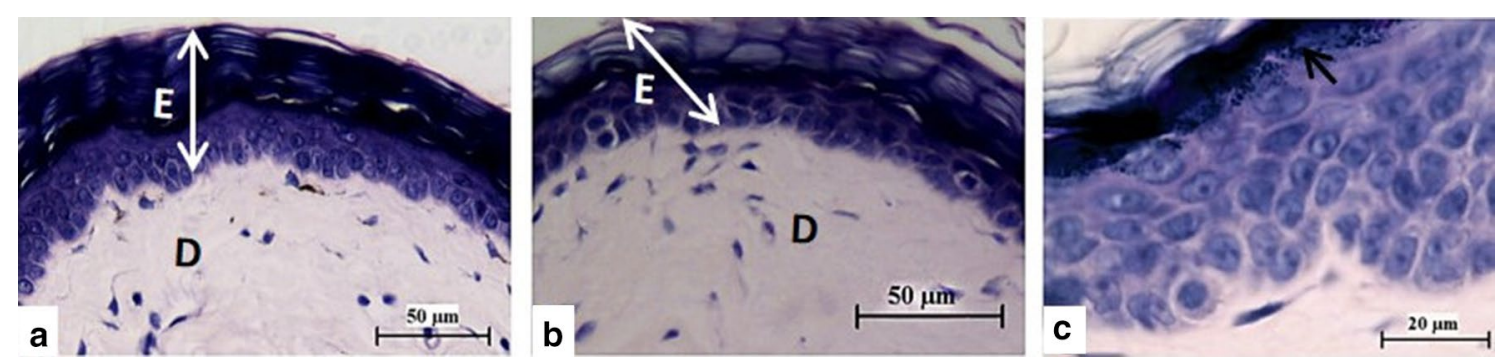

Fig. 2 Histological sections of NMR skin from the shoulder region obtained after topical application of Vaseline (a) and imiquimod cream (b) for eight days. There are no changes in the skin structure after application of Vaseline or IMQ, with no leucocyte infiltration nor vascular congestion and the straight boundary between epidermis (E) and dermis (D) is maintained. Epidermis of NMR that received topical IMQ for 8 days (c) showing a well-formed stratum granulosum (arrow)

there was no vascular congestion nor leucocyte infiltration.

\section{Discussion}

Topical application of IMQ elicits an inflammatory reaction in murine skin characterized grossly by erythema and scaling. Histologically, the features include epidermal thickening, altered epidermal differentiation with retention of nuclei in stratum corneum, absence of epidermal granular layer and leukocyte infiltration in the dermis [31-33]. These features closely resemble human psoriasis so well that this regimen has been suggested as a fast and reproducible model of studying the condition [31, 43]. The effects of IMQ are mediated by TLR $7 / 8$ which are mainly expressed by monocytes, macrophages and dendritic cells [31]. Studies have also suggested that IMQ also act on keratinocytes either through TLR 7 [44] or a TLR-independent mechanism [45].

The results of this study suggest that the skin of NMR shows neither TLR-mediated nor TLR-independent effects of IMQ. This finding is intriguing and affirms the uniqueness and possibly the exceptional nature of inflammatory/immune response of this animal. Recent findings have shown that innate immunity of NMR possesses a number of differences, in terms of cellular composition, from what is generally known in mammals [46]. It is therefore probable that the inflammatory/immuno-surveillance components/mechanisms in the NMR epidermis that would initiate IMQ-induced skin reactions are different from that of other mammals. NMR may either be possessing, within the epidermis, atypical Langerhans cells and/or plasmacytoid dendritic cells that lack the mechanisms that mediate IMQ responses. These cells are thought to form the first line of contact with IMQ via their TLR $7 / 8$ thus mediating the effects $[47,48]$. Future studies aiming at immunohistolocalization of Langerhans cells and TLR 7 in the NMR skin may clarify this. Although a clear explanation to the non-reaction of NMR skin to IMQ could not be adduced, our results affirm the exceptional and unique nature of NMR inflammation/ immunity. Furthermore, inflammation has been established as a hallmark of cancer [49-51] and it is therefore likely that the unique inflammatory/immunosurveillance mechanism exhibited by this animal could also be a contributor to its resistance to cancer.

In studies using mice, IMQ was applied on shaven area over the dorsum of the animal. Shaving before application could be significant as it has been suggested to enhance percutaneous absorption of substances [52, 53]. Being hairless, neither shaving nor sham-shaving was 
performed before IMQ application in the NMR. This could therefore mean that in the study using NMR, IMQ was applied to a more intact barrier and therefore the access to the cells that mediate the IMQ effects was limited if not eliminated. Furthermore, the NMR is thought to have a thicker epidermis and stratum corneum [7]. It is also possible that in this animal, Langerhans cells are localized in the dermis rather than in epidermis. This makes the cells virtually inaccessible to the ligand (IMQ) for their TLR 7/8. Such an atypical distribution of epidermal cells to the dermis in this animal has been reported in regard to the melanocytes [7].

Reactive oxygen species (ROS) are reported to play a protective role against immune mediated diseases. Increasing ROS has been shown to attenuate IMQinduced psoriatic dermatitis while administration of antioxidant, N-Acetylcysteine, aggravated the condition [54]. NMR has poor antioxidant capacity, a more pro-oxidative cellular environment and higher levels of oxidative damage to macromolecules as compared to age-matched mice [55-57]. It is possible that there are high ROS in the skin of NMR which in turn confers protection against IMQ-induced psoriasis-like inflammation. This hypothesis, however, needs to be backed by further studies to analyze antioxidant capacity, oxidative damage and prooxidative status of NMR skin.

In conclusion, topical application of IMQ does not induce psoriaform skin inflammation in the NMR. This could be due to a combination of various unique attributes of the animal's skin structure and/or its inflammatory/immunosurveillance apparatus. The cells that interact with IMQ and mediate its effects may have atypical distribution such that access to IMQ is limited or they could also be lacking TLR 7/8 and other mechanisms that mediate IMQ effects. High ROS reported in NMR tissues could also be exhibited by the skin and thereby compounding its resistance or tolerance to IMQ. The animal could be a good negative model for studying psoriasis but as a prerequisite, further studies are necessary to characterize the mechanisms behind the non-reaction of the animal's skin to IMQ.

\section{Limitations}

This study was designed to characterize inflammatory responses of NMR skin to topical IMQ. Unexpectedly, the results turned out negative. It is our strong opinion that this observation is significant and of great scientific value. Naturally, this would have been followed by further experiments to explain in detail the mechanism behind non-response. Unfortunately, resources needed to fulfil this are not immediately available. It is therefore important that this information is shared with the scientific community to stimulate further research that will build on our results through collaborations or otherwise.

\section{Supplementary information}

Supplementary information accompanies this paper at https://doi. org/10.1186/s13104-020-05260-6.

Additional file 1: Figure S1. Photographs of NMR. There were no changes in the skin after application of either Vaseline (a) or imiquimod (b). These agents were applied in the region bound by dotted line.

Additional file 2: Figure S2. Histological sections of NMR skin from the rump region from animals that received topical application of Vaseline (a) and imiquimod cream (b). There are no changes in the skin structure after application of Vaseline or IMQ for 8 days, with no infiltration by leucocytes and maintenance of a straight boundary between epidermis (E) and dermis (D).

\section{Abbreviations}

NMR: Naked mole rat; IMQ: Imiquimod; TLR: Toll-like receptor; $\mathrm{cm}^{2}$ : Square centimeters; ROS: Reactive oxygen species.

\section{Acknowledgements}

The authors wish to acknowledge Messrs Gilbert Mwanthi and Bonventure Mutiso both from the Department of Animal \& Veterinary Sciences, South Eastern Kenya University for their input in animal handling and care. We are also grateful to Mr. Francis Okumu of the Department of Veterinary Anatomy and Physiology, University of Nairobi for processing the tissues for histology.

\section{Authors' contributions}

All authors took part in the design of the study. MLK administered the test agents. MLK, ROO, TIK did macroscopic examinations. MLK, KSPA, ROO, TIK performed histological examination and analyses besides the blinded examiners. MLK did the drafted the manuscript, which was reviewed by KSPA, ROO, TIK. All authors read and approved the final manuscript.

\section{Funding}

This study was conducted using funds provided by the Department of Experimental Medicine, University of Copenhagen.

\section{Availability of data and materials}

All the data and results generated and analyzed have been presented in this published article and its supplementary information files.

\section{Ethics approval and consent to participate}

The animals used in this study were captured under the permit KWS/ BRM/50001 from the Kenya Wildlife Service (KWS). The study was approved by the Biosafety, Animal Use and Ethics Committee of the Faculty of Veterinary Medicine, University of Nairobi.

\section{Consent for publication}

Not applicable.

\section{Competing interests}

The authors declare that they have no competing interests.

\section{Author details \\ ${ }^{1}$ Department of Veterinary Anatomy \& Physiology, Egerton University, Egerton, P.O. Box 536, Nakuru 20115, Kenya. ${ }^{2}$ Department of Veterinary Anatomy \& Physiology, University of Nairobi, P.O. Box 30197, Nairobi 00100, Kenya. ${ }^{3}$ Department of Agricultural Sciences, South Eastern Kenya University, P.O. Box 170, Kitui 90200, Kenya. ${ }^{4}$ Department of Experimental Medicine, University of Copenhagen, Blegdamsvej 3B, 2200 Copenhagen, Denmark.}




\section{References}

1. Bourke A. The biology of the naked mole-rat. Trends Ecol Evol. 1991;6:171-2. https://doi.org/10.1016/0169-5347(91)90064-5.

2. Schuhmacher L-N, Husson Z, Smith ESJ. The naked mole-rat as an animal model in biomedical research: current perspectives. Open Access Anim Physiol. 2015;7:137-48. https://doi.org/10.2147/OAAP.S50376.

3. Jarvis JUM. Eusociality in a mammal: cooperative breeding in naked mole-rat colonies. Science. 1981;212:571-3. https://doi.org/10.1126/scien ce.7209555.

4. Buffenstein R. The naked mole-rat: a new long-living model for human aging research. J Gerontol Ser A Biol Sci Med Sci. 2005;60:1369-77. https ://doi.org/10.1093/gerona/60.11.1369.

5. Edrey $Y H$, Hanes M, Pinto M, Mele J, Buffenstein R. Successful aging and sustained good health in the naked mole rat: a long-lived mammalian model for biogerontology and biomedical research. ILAR J. 2011;52:4153. https://doi.org/10.1093/ilar.52.1.41.

6. Fang X, Seim I, Huang Z, Gerashchenko MV, Xiong Z, Turanov AA, et al. Adaptations to a subterranean environment and longevity revealed by the analysis of mole rat genomes. Cell Rep. 2014. https://doi. org/10.1016/j.celrep.2014.07.030.

7. Daly JTM, Buffenstein R. Skin morphology and its role in thermoregulation in mole-rats, Heterocephalus glaber and Cryptomys hottentotus. J Anat. 1998;193:495-502.

8. Tsoi LC, Spain SL, Knight J, Ellinghaus E, Stuart PE, Capon F, et al. Identification of 15 new psoriasis susceptibility loci highlights the role of innate immunity. Nat Genet. 2012;44:1341-8.

9. Rendon A, Schäkel K. Psoriasis pathogenesis and treatment. Int J Mol Sci. 2019;20:1475. https://doi.org/10.3390/ijms20061475.

10. Parisi R, Symmons DPM, Griffiths CEM, Ashcroft DM. Global epidemiology of psoriasis: a systematic review of incidence and prevalence. J Invest Dermatol. 2013:133:377-85. https://doi.org/10.1038/jid.2012.339.

11. Enamandram M, Kimball AB. Psoriasis epidemiology: the interplay of genes and the environment. J Invest Dermatol. 2013;133:287-9. https:// doi.org/10.1038/jid.2012.434.

12. Korman NJ. Management of psoriasis as a systemic disease: what is the evidence? Br J Dermatol. 2019;182:840. https://doi.org/10.1111/bjd.18245

13. Lai CY, Su YW, Lin Kl, Hsu LC, Chuang TH. Natural modulators of endosomal Toll-Like receptor-mediated psoriatic skin inflammation. J Immunol Res 2017;2017. https://doi.org/10.1155/2017/7807313.

14. Kim WB, Jerome D, Yeung J. Diagnosis and management of psoriasis. Can Fam Physician. 2017;63:278-85.

15. Sundarrajan S, Arumugam M. Comorbidities of psoriasis-exploring the links by network approach. PLoS ONE. 2016;11:0149175. https://doi. org/10.1371/journal.pone.0149175.

16. Lowes MA, Suárez-Fariñas M, Krueger JG. Immunology of psoriasis. Annu Rev Immunol. 2014;32:227-55. https://doi.org/10.1146/annurev-immun ol-032713-120225.

17. Ayala-Fontanez N, Soler D, McCormick T. Current knowledge on psoriasis and autoimmune diseases. Psoriasis Targets Ther. 2016;6:7-32. https://doi. org/10.2147/ptt.s64950.

18. Zhao J, Di T, Wang Y, Wang Y, Liu X, Liang D, et al. Paeoniflorin inhibits imiquimod-induced psoriasis in mice by regulating Th17 cell response and cytokine secretion. Eur J Pharmacol. 2016. https://doi.org/10.1016/j. ejphar.2015.12.040.

19. Arits AHMM, Mosterd K, Essers BA, Spoorenberg E, Sommer A, De Rooij MJM, et al. Photodynamic therapy versus topical imiquimod versus topical fluorouracil for treatment of superficial basal-cell carcinoma: a single blind, non-inferiority, randomised controlled trial. Lancet Oncol. 2013;14:647-54. https://doi.org/10.1016/S1470-2045(13)70143-8.

20. Arits AHMM, Spoorenberg E, Mosterd K, Nelemans P, Kelleners-Smeets NWJ, Essers BAB. Cost-effectiveness of topical imiquimod and fluorouracil vs. photodynamic therapy for treatment of superficial basal-cell carcinoma. Br J Dermatol. 2014;171:1501-7. https://doi.org/10.1111/bjd.13066

21. Paoli J, Gyllencreutz JD, Fougelberg J, Backman EJ, Modin M, Polesie S, et al. Nonsurgical options for the treatment of basal cell carcinoma. Dermatol Pract Concept. 2019;9:75-81. https://doi.org/10.5826/dpc.0902a01.

22. Edwards L, Ferenczy A, Eron L, Baker D, Owens ML, Fox TL, et al. Selfadministered topical 5\% imiquimod cream for external anogenital warts. HPV Study Group. Human PapillomaVirus. Arch Dermatol. 1998;134:25-30.

23. Hengge UR, Esser S, Schultewolter T, Behrendt C, Meyer T, Stockfleth E, et al. Self-administered topical 5\% imiquimod for the treatment of common warts and molluscum contagiosum. Br J Dermatol. 2000;143:102631. https://doi.org/10.1046/j.1365-2133.2000.03777.x.

24. Gollnick H, Dirschka T, Ostendorf R, Kerl H, Kunstfeld R. Long-term clinical outcomes of imiquimod $5 \%$ cream versus diclofenac $3 \%$ gel for actinic keratosis on the face or scalp: a pooled analysis of two randomized controlled trials. J Eur Acad Dermatology Venereol. 2020;34:82-9. https:// doi.org/10.1111/jdv.15868.

25. Altalhab S. The effectiveness of imiquimod $5 \%$ cream as an anti-wrinkle treatment: a pilot study. J Cosmet Dermatol. 2019;18:1729-32. https://doi. org/10.1111/jocd.12939.

26. Hanna E, Abadi R, Abbas O. Imiquimod in dermatology: an overview. Int J Dermatol. 2016:55:831-44. https://doi.org/10.1111/ijd.13235.

27. Wu JK, Siller G, Strutton G. Psoriasis induced by topical imiquimod. Australas J Dermatol. 2004:45:47-50.

28. Fanti PA, Dika E, Vaccari S, Miscial C, Varotti C. Generalized psoriasis induced by topical treatment of actinic keratosis with imiquimod. Int J Dermatol. 2006;45:1464-5. https://doi.org/10.111 1/j.1365-4632.2006.02980.x.

29. Varma SR, Sivaprakasam TO, Mishra A, Prabhu S, Rafiq M, Rangesh P. Imiquimod-induced psoriasis-like inflammation in differentiated Human keratinocytes: Its evaluation using curcumin. Eur J Pharmacol. 2017;813:33-41. https://doi.org/10.1016/j.ejphar.2017.07.040.

30. Flutter B, Nestle FO. TLRs to cytokines: Mechanistic insights from the imiquimod mouse model of psoriasis. Eur J Immunol. 2013;43:3138-46. https://doi.org/10.1002/eji.201343801.

31. van der Fits L, Mourits S, Voerman JSA, Kant M, Boon L, Laman JD, et al. Imiquimod-induced psoriasis-like skin inflammation in mice is mediated via the IL-23/IL-17 axis. J Immunol. 2009;182:5836-45. https://doi. org/10.4049/jimmunol.0802999.

32. Luo DQ, Wu HH, Zhao YK, Liu JH, Wang F. Different imiquimod creams resulting in differential effects for imiquimod-induced psoriatic mouse models. Exp Biol Med. 2016;241:1733-8. https://doi.org/10.1177/15353 70216647183.

33. Dou R, Liu Z, Yuan X, Xiangfei D, Bai R, Bi Z, et al. PAMs ameliorates the imiquimod-induced psoriasis-like skin disease in mice by inhibition of translocation of NF-kB and production of inflammatory cytokines. PLoS ONE. 2017;12:e0176823. https://doi.org/10.1371/journal.pone.0176823.

34. Wohn CT, Pantelyushin S, Ober-Blöbaum JL, Clausen BE. Aldara-induced psoriasis-like skin inflammation: isolation and characterization of cutaneous dendritic cells and innate lymphocytes. Methods Mol Biol. 2014;1193:171-85. https://doi.org/10.1007/978-1-4939-1212-4_16.

35. Ilacqua AN, Kirby AM, Pamenter ME. Behavioural responses of naked mole rats to acute hypoxia and anoxia. Biol Lett. 2017;13:20170545. https ://doi.org/10.1098/rsbl.2017.0545.

36. Park TJ, Lu Y, Jüttner R, Smith ESJ, Hu J, Brand A, et al. Selective inflammatory pain insensitivity in the African naked mole-rat (Heterocephalus glaber). PLoS Biol. 2008;6:e13. https://doi.org/10.1371/journal.pbio.00600 13.

37. Smith SJE, Blass GR, Lewin GR, Park TJ. Absence of histamine-induced itch in the African naked mole-rat and "Rescue" by substance P. Mol Pain. 2010;6:29. https://doi.org/10.1186/1744-8069-6-29.

38. Liang S, Mele J, Wu Y, Buffenstein R, Hornsby PJ. Resistance to experimental tumorigenesis in cells of a long-lived mammal, the naked mole-rat (Heterocephalus glaber). Aging Cell. 2010;9:626-35. https://doi.org/10.111 1/j.1474-9726.2010.00588.x.

39. Seluanov A, Hine C, Azpurua J, Feigenson M, Bozzella M, Mao Z, et al. Hypersensitivity to contact inhibition provides a clue to cancer resistance of naked mole-rat. Poc Nat'l Acad Sci. 2009;106:19352-7.

40. Tian X, Azpurua J, Hine C, Vaidya A, Myakishev-Rempel M, Ablaeva J, et al. High-molecular-mass hyaluronan mediates the cancer resistance of the naked mole rat. Nature. 2013;499:346-9. https://doi.org/10.1038/natur e12234.

41. Petruseva IO, Evdokimov AN, Lavrik Ol. Genome stability maintenance in naked mole-rat. Acta Naturae. 2017;9:31-41.

42. Mead R. The design of experiments : statistical principles for practical applications. Cambridge: Cambridge University Press; 1988. 
43. El Malki K, Karbach SH, Huppert J, Zayoud M, Reißig S, Schüler R, et al. An alternative pathway of imiquimod-induced psoriasis-like skin inflammation in the absence of interleukin-17 receptor a signaling. J Invest Dermatol. 2013. https://doi.org/10.1038/jid.2012.318.

44. Li ZJ, Sohn KC, Choi DK, Shi G, Hong D, Lee HE, et al. Roles of TLR7 in activation of NF-KB signaling of keratinocytes by imiquimod. PLOS ONE. 2013;8:e77159. https://doi.org/10.1371/journal.pone.0077159.

45. Walter A, Schäfer M, Cecconi V, Matter C, Urosevic-Maiwald M, Belloni B, et al. Aldara activates TLR7-independent immune defence. Nat Commun. 2013;4:1560. https://doi.org/10.1038/ncomms2566.

46. Hilton HG, Rubinstein ND, Janki P, Ireland AT, Bernstein N, Fong NL, et al. Single-cell transcriptomics of the naked mole-rat reveals unexpected features of mammalian immunity. PLOS Biol. 2019;17:e3000528. https:// doi.org/10.1371/journal.pbio.3000528.

47. Garzorz-Stark N, Lauffer F, Krause L, Thomas J, Atenhan A, Franz R, et al. Toll-like receptor $7 / 8$ agonists stimulate plasmacytoid dendritic cells to initiate TH17-deviated acute contact dermatitis in human subjects. J Allergy Clin Immunol. 2018;141(1320-1333):e11. https://doi. org/10.1016/j.jaci.2017.07.045.

48. Deckers J, Hammad H, Hoste E. Langerhans cells: Sensing the environment in health and disease. Front Immunol. 2018;9:93. https://doi. org/10.3389/fimmu.2018.00093.

49. Greten FR, Grivennikov SI. Inflammation and cancer: triggers, mechanisms, and consequences. Immunity. 2019;51:27-41. https://doi. org/10.1016/j.immuni.2019.06.025.

50. Lu H, Ouyang W, Huang C. Inflammation, a key event in cancer development. Mol Cancer Res. 2006;4:221-33. https://doi.org/10.1158/1541-7786. MCR-05-0261.

51. Sui X, Lei L, Chen L, Xie T, Li X. Inflammatory microenvironment in the initiation and progression of bladder cancer. Oncotarget. 2017;8:93279-94. https://doi.org/10.18632/oncotarget.21565.
52. Hamza M, Tohid $H$, Maibach $H$. Shaving effects on percutaneous penetration: clinical implications. Cutan Ocul Toxicol. 2015;34:335-43. https://doi. org/10.3109/15569527.2014.966109.

53. Pany A, Klang V, Brunner M, Ruthofer J, Schwarz E, Valenta C. Effect of physical and chemical hair removal methods on skin barrier function in vitro: consequences for a hydrophilic model permeant. Skin Pharmacol Physiol. 2019;32:8-21. https://doi.org/10.1159/000493168.

54. Kim H-R, Lee A, Choi E-J, Hong M-P, Kie J-H, Lim W, et al. Reactive oxygen species prevent imiquimod-induced psoriatic dermatitis through enhancing regulatory T cell function. PLoS ONE. 2014;9:e91146. https:// doi.org/10.1371/journal.pone.0091146.

55. Andziak B, O'Connor TP, Qi W, Dewaal EM, Pierce A, Chaudhuri AR, et al. High oxidative damage levels in the longest-living rodent, the naked mole-rat. Aging Cell. 2006;5:463-71. https://doi.org/10.111 1/j.1474-9726.2006.00237.x.

56. Saldmann F, Viltard M, Leroy C, Friedlander G. The naked mole rat: a unique example of positive oxidative. Stress. 2019. https://doi. org/10.1155/2019/4502819.

57. Andziak B, Buffenstein R. Disparate patterns of age-related changes in lipid peroxidation in long-lived naked mole-rats and shorterlived mice. Aging Cell. 2006;5:525-32. https://doi.org/10.111 $1 / j .1474-9726.2006 .00246 . x$

\section{Publisher's Note}

Springer Nature remains neutral with regard to jurisdictional claims in published maps and institutional affiliations.
Ready to submit your research? Choose BMC and benefit from:

- fast, convenient online submission

- thorough peer review by experienced researchers in your field

- rapid publication on acceptance

- support for research data, including large and complex data types

- gold Open Access which fosters wider collaboration and increased citations

- maximum visibility for your research: over $100 \mathrm{M}$ website views per year

At BMC, research is always in progress.

Learn more biomedcentral.com/submissions 